\author{
Hristina Vlajinac \\ Sandra Šipetić \\ Eleonora Džoljić \\ Jadranka Maksimović \\ Jelena Marinković \\ Vlada Kostić
}

\section{Some lifestyle habits of female Belgrade university students with migraine and non-migraine primary headache}

Received: 29 July 2002

Accepted in revised form: 3 March 2003

H. Vlajinac (西) • S. Šipetić • J. Maksimović Institute of Epidemiology,

School of Medicine,

Belgrade University,

Višegradska 26, 11000 Belgrade, Yugoslavia

e-mail: sandragru@ptt.yu

Tel.: +381-11-361-57-71

Fax: +381-11-361-57-68

\section{E. Džoljić • V. Kostić}

Institute of Neurology,

School of Medicine,

Belgrade University,

Belgrade, Yugoslavia

J. Marinković

Institute of Social Medicine, Statistics and

Health Research,

School of Medicine,

Belgrade University,

Belgrade, Yugoslavia

\author{
Abstract We performed a preva- \\ lence study to compare some \\ lifestyle habits between subjects \\ with migraine and those with non- \\ migraine primary headaches. We \\ surveyed female students in ran- \\ domly selected classes of the \\ School of Medicine and the School \\ of Pharmacy, Belgrade University. \\ Among all observed students (1943 \\ subjects), 245 had migraine and \\ 1053 had non-migraine primary \\ headache. According to multivariate \\ logistic regression analysis, the fol- \\ lowing factors were associated with \\ migraine: irregular eating (odds \\ ratio $(\mathrm{OR})=1.99 ; 95 \%$ confidence \\ interval $(95 \% \mathrm{CI}), 1.69$ to 2.34 ; \\ $p<0.01$ ), sleep duration shorter than \\ usual $(\mathrm{OR}=1.18 ; 95 \%$ CI 1.00 to \\ $1.38 ; p=0.0449)$ and smoking $>10$ \\ cigarettes per day $(\mathrm{OR}=1.18 ; 95 \%$ \\ $\mathrm{CI}=1.00$ to $1.39 ; p=0.0433)$. The
}

results of the present study are in line with some other investigations suggesting that some lifestyle habits probably play a role as migraine precipitants.

\section{Introduction}

An increasing body of evidence from migraine research, particularly migraine pathophysiology, indicates that migraine sufferers have a unique phenotype of attacks with underlying specific biotype of migraine disorder, namely "the sensitive brain" [1-3]. Such a defective pain control system is unstable and may respond by a continuous discharge when subjected to stimulation from higher centers (e.g. cortex, hypothalamus) as the result of stress or by excessive afferent input from the special senses or from cerebral or extracranial vessels [4]. Precipitants are not universal because the presence of a factor does not always trigger an attack in the same person, and only subgroups of headache sufferers are sensitive to any specific factor. Therefore a multifactorial trigger mechanism for particular attacks has been suggested [5]. It is more likely that endogenous and exogenous factors must coincide in order to precipitate attacks in most migraineurs.

This paper presents data about some lifestyle habits of female Belgrade University students suffering from migraine in comparison with students with non-migraine primary headache. 
1. Have you ever had at least one headache not due to head injury, hangover, pregnancy, or an illness such as cold or flu?

1. NO YES

2. If YES, have you always had a similar type of headache?

1. NO 2 YES

3. If NO, how many different types of headache do you have:

a. One

b. Two

c. Three

d. More (how many:

The following questions define your the most severe type of headache:

4. Define the level of your headache on a scale of 1 to 10 :

5. At what age did your headache begin?

6. What is the frequency of your headache?

Monthly: Per year:

7. What is the number of occurrence of your headache:

a. $1-4$

b. $5-10$

c. 11 or more

8. What is the average duration of your headache (in hours)?

9. Have you ever had unilateral headache?

10. If YES, how often (frequently)?

$\begin{array}{lll}\text { a. Rarely } & \text { b. Half the time }\end{array}$

c. Often d. Always

11. Have you ever had pulsatile headache?

12. If YES, how often:
a. Rarely
b. Half the time
c. Often
d. Always

13. Has your headache ever been exacerbated by physical activity?

14. If YES, how often?
a. Rarely
b. Half the time
c. Often
d. Always

15. Has your headache ever been associated with nausea?

16. If YES, how often?
a. Rarely
b. Half the time
c. Often
d. Always

17. Has your headache ever been associated with vomiting?

18. If YES, how often?
a. Rarely
b. Half the time
c. Often
d. Always

19. Has your headache ever been associated with the photophobia?

20. If YES, how often?
a. Rarely
b. Half the time
c. Often
d. Always

21. Has your headache ever been associated with phonophobia?

22. If YES, how often?
a. Rarely
b. Half the time
c. Often
d. Always

23. Have you ever had any of the following symptoms before or during headache:

a. Homonymous visual disturbance

b. Unilateral paresthesia or numbness

c. Unilateral weakness

d. Aphasia or unclassifiable speech difficulty

24. If YES, how did the symptoms develop? $\begin{array}{ll}\text { a. Immediately } & \text { b. Gradually, over more than } 4 \text { minutes }\end{array}$

25. What is the duration of such symptoms:
a. Less than $1 \mathrm{~h}$
b. More than $1 \mathrm{~h}$

26. When did these symptoms occur:

a. Less than $1 \mathrm{~h}$ before headache

b. Simultaneously with your headache

c. After the occurrence of your headache

Fig. 1 The questionnaire for migraine and headache 


\section{Materials and methods}

The study was conducted in Belgrade from February to June 2000. The investigation comprised female students of the School of Medicine and the School of Pharmacy of University of Belgrade, Yugoslavia. A questionnaire (Fig. 1) was administered to 1943 students during randomly selected classes. In addition to personal data, participants were asked whether they ever had experienced at least one headache, which was not caused by a head injury, pregnancy, hangover, or acute illness. Detailed questions were asked regarding the most severe type of headache: the duration of the headache, the frequency of headache, the average number of headache attacks per month or per year, as well as regarding the duration, location, quality, and intensity of their headache, the influence of physical activity upon their headache, the occurrence of nausea, vomiting, photophobia, or phonophobia, and the occurrence and duration of associated neurological symptoms. The main purposes of the study were to estimate the prevalence of migraine and non-migraine primary headache [6], and at the same time to obtain data about hormonal characteristics and regularity of sleeping, eating and smoking habits. The study was conducted according to the ethical principles established in the Declaration of Helsinki.

Migraine diagnosis was assigned using criteria of the International Headache Society [7] and MacGregor's stricter definition [8] of "menstrual migraine" as migraine attacks exclusively starting on the first day of menstruation \pm 2 days and at no other time of the menstrual cycle. "Menstrually associated migraines" were defined as migraine attacks occurring not only at menses, but also at other times of the month and aggravated during menstruation. "Premenstrual migraine" was defined as migraine attacks occurring 2-7 days prior to the onset of menses. "Menstrually unchanged migraine" was defined as migraine that occurs at menses and at other times of the month, and does not change during menstruation. Migraines unrelated to menses, as well as the primary nonmigraine headaches related to the menstrual cycle in the same way as migraines, were also analyzed.

In the analysis of data obtained, proportions, chi-square test and multivariate logistic regression analysis were used.

In this paper only data about lifestyle habits of female students with migraine and non-migraine primary headaches are presented.

\section{Results}

Of 1943 female students (18-28 years of age), 1298 (66.8\%) had primary headaches. Among 1298 students with headache, 245 had migraine and 1053 had non-migraine headache, the prevalence rates being $12.6 \%$ and $54.2 \%$, respectively. Female students with migraine and non-migraine headaches were comparable regarding age $(\approx 22$ years), onset of migraine or onset of non-migraine headaches [6].

Some lifestyle characteristics of migraineurs and students with non-migraine primary headache are presented in Table 1 . The average number of meals per day was similar
Table 1 Some lifestyle habits of female students with migraine and non-migraine primary headaches

\begin{tabular}{|c|c|c|c|}
\hline Characteristic & $\begin{array}{c}\text { Migraine } \\
\mathrm{n}(\%)\end{array}$ & $\begin{array}{l}\text { Non-migraine } \\
\text { headaches, } \\
\text { n }(\%)\end{array}$ & $\begin{array}{c}p \\
\text { value }^{\mathrm{a}}\end{array}$ \\
\hline \multicolumn{4}{|c|}{ Average number of meals per day } \\
\hline$<3$ & $73(29.8)$ & $261(25.5)$ & \multirow[t]{3}{*}{0.3894} \\
\hline 3 & $135(55.1)$ & $602(58.7)$ & \\
\hline$>3$ & $37(15.1)$ & $162(15.8)$ & \\
\hline \multicolumn{4}{|c|}{ Missed meals, frequency per month: } \\
\hline 0 & $36(14.7)$ & $533(50.6)$ & \multirow[t]{4}{*}{$<0.001$} \\
\hline $1-9$ & $93(38.0)$ & $320(30.4)$ & \\
\hline $10-20$ & $99(40.4)$ & $165(15.7)$ & \\
\hline$>20$ & $17 \quad(6.9)$ & $35 \quad(3.3)$ & \\
\hline \multicolumn{4}{|c|}{ Average duration of sleep, $\mathrm{h}$} \\
\hline$\leq 6$ & $49(20.0)$ & $137(13.4)$ & \multirow[t]{3}{*}{0.0087} \\
\hline $7-8$ & $167(68.2)$ & $704(69.2)$ & \\
\hline$\geq 9$ & $29(11.8)$ & $177(17.4)$ & \\
\hline \multicolumn{4}{|c|}{ Sleep duration less than usual, frequency per month } \\
\hline 0 & $62(25.3)$ & $386(36.6)$ & \multirow[t]{4}{*}{0.0012} \\
\hline $1-5$ & $83(33.9)$ & $336(31.9)$ & \\
\hline $6-10$ & $72(29.4)$ & $263(25.0)$ & \\
\hline$>10$ & $28(11.4)$ & $68 \quad(6.5)$ & \\
\hline \multicolumn{4}{|c|}{ Sleep duration more than usual, frequency per month } \\
\hline 0 & $107(43.7)$ & $542(51.5)$ & \multirow[t]{3}{*}{0.0456} \\
\hline $1-5$ & $95(38.8)$ & $376(35.7)$ & \\
\hline$>5$ & $43(17.5)$ & $135(12.8)$ & \\
\hline $\begin{array}{l}\text { Smoking habit, } \\
\text { actual or previous }\end{array}$ & $113(46.1)$ & $422(40.1)$ & 0.0833 \\
\hline \multicolumn{4}{|c|}{ Cigarettes smoked, n/day } \\
\hline$<10$ & $26(23.0)$ & $165(39.1)$ & \multirow[t]{2}{*}{0.0015} \\
\hline$\geq 10$ & $87(77.0)$ & $257(60.9)$ & \\
\hline
\end{tabular}

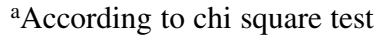

in the groups, but missing a meal was more frequently reported by migraineurs $(p<0.05)$. A significantly greater percentage of students with migraine than those with nonmigraine primary headache reported shorter duration of usual sleep (less than 6 hours per day), and the opposite was true for duration of usual sleep $\geq 9$ hours per day ( $p=0.0087$ ). Significant differences between these two goups were also found for changes in sleeping pattern. Migraineurs more frequently reported both shorter and longer sleep durations than usual ( $p=0.0012$ and $p=0.0456$, respectively). The percent of ever-smokers was a bit higher among migraineurs than among students with non-migraine primary headache $(p=0.0833)$, and migraineurs smoked a greater number of cigarettes per day $(p=0.0015)$.

All variables that according to $\chi^{2}$ test were related to migraine at a significance level of $p \leq 0.10$ were put in a model of multivariate logistic regression analysis. According to 
multivariate analysis, the following factors were significantly associated with migraine: irregular eating (odds ratio $(\mathrm{OR})=1.99 ; 95 \%$ confidence interval $(95 \% \mathrm{CI}), 1.69$ to 2.34 ; $p<0.001)$, sleep duration shorter than usual $(\mathrm{OR}=1.18 ; 95 \%$ $\mathrm{CI}=1.00$ to $1.38 ; p=0.0449)$ and smoking $>10$ cigarettes per day $(\mathrm{OR}=1.18 ; 95 \% \mathrm{CI}=1.00$ to $1.39 ; p=0.0433)$.

\section{Discussion}

Migraine headache is considered to be a result of the inability of the nervous system to adapt to changes in the endogenous and exogenous environments. The changes could be hormonal, behavioural, dietary and environmental [9].

Many studies (e.g. patient surveys, randomized controlled and prospective diary studies) have been designed in order to answer the question "What triggers a migraine headache?" Taking into account that a reliance on self-reporting is subject to significant recall bias and that it generally leads to over-reporting of a given risk factor, in the present study we decided not to ask our participants questions about factors which they associated with the development of headache, but to ask questions about some of their lifestyle habits. These questions were located at the end of the questionnaire, unrelated to questions about headaches.

In the present study, missing a meal, changes in sleeping pattern (shorter than usual) and smoking $>10$ cigarettes per day were significantly related to migraine. According to the literature, all these factors have been considered as migraine precipitants $[5,9,10]$.

Fasting and sleep disturbances have been shown to be general headache triggers acting on a central basis [9-14]. Their role as migraine precipitants has been considered as probable and possible [9]. Fasting was reported as a trigger by $40 \%-50 \%$ of migraineurs $[14,15]$. Both undersleeping and oversleeping were described as triggers of migraine [11, 13]. Sleep disturbances as migraine precipitants were found in $31 \%-50 \%$ of migraineurs $[14,15]$. Shorter sleep duration and some other sleep disturbances were reported to be more frequent among children and adolescents with migraine and tension-type headache than among controls [16]. Sleep disturbances could alter neuronal firing rates within migrainespecific brainstem modulatory pathways, which could lead to migraine headache $[4,9,10]$. Sleep may itself play a role in the resolution of migraine attack [9].

Data about smoking as a precipitant of migraine are inconsistent $[9,13,14,16,17]$. In the present study, students with migraine were ever-smokers more frequently than students with non-migraine primary headache, but the difference was not significant. However, a significantly higher proportion of migraineurs smoked more than 10 cigarettes per day. Only a few students in both groups were heavy smokers ( $>25$ cigarettes per day). Some epidemiological data suggest that smoking may influence the pattern of headaches in migraineurs [9]. A higher severity of headaches among smokers than among non-smokers has been reported, but the data are still insufficient to prove a causal link between cigarette smoking and a worsening of migraine [9].

On the basis of the results obtained, it is not possible to conclude that irregular eating, sleep duration shorter than usual and smoking $>10$ cigarettes per day act as triggers of migraine attacks. All these life characteristics could be symptoms of the migraine prodrome or could even be consequences of migraine (one cannot eat because of headache, cannot sleep or sleeps longer or shorter than usual or smokes because of headache). It is also possible that the results were influenced by some confounding variables not taken into account in this study. Nevertheless, the results of the present study are in line with some other investigations suggesting that some lifestyle habits probably play a role as migraine precipitants.

Acknowledgments This work was supported by the Ministry of Science, Technology and Development of Serbia through contract no. 8774 (1996-2000).

\section{References}

1. Goadsby JP (2001) Pathophysiology of headache. In: Silberstein SS, Lipton RB, Dalessio DJ (eds) Wolff's headache and other head pain. Oxford University, Oxford, pp 57-72

2. Velso F, Kumar K, Toth C (1998) Headache secondary to deep brain implantation. Headache 38:507-515

3. Weiller C, May A, Limmroth V (1995) Brain stem activation in spontaneous activation in spontaneous human migraine attacks. Nat Med 1:658-660
4. Lance JW, Goadsby PJ (1999) Migraine: pathophysiology. In: Lance JW, Goadsby PJ (eds) Mechanism and management of headache. Butterworth Heineman, Oxford, pp 79-116

5. Zagami AS, Rasmussen BK (2000) Symptomatology of migraine without aura. In: Olesen J, Tfelt-Hansen P, Welch KMA (eds) The headaches. Lippincott Williams Willkins, Philadelphia, pp 331-336
6. Dzoljic E, Sipetic S, Vlajinac H, Marinkovic J, Brzakovic B, Pokrajac M, Kostic V (2002) Prevalence of menstrually related migraine and nonmigraine primary headache in female students of Belgrade University. Headache 42:185-194

7. - (1988) Classification and diagnostic criteria disorders, cranial neuralgia and facial pain. Headache Classification Committee of International Headache Society. Cephalalgia 8[Suppl 7]:20 
8. MacGregor EA (1996) "Menstrual" migraine: towards a definition. Cephalalgia 16:11-21

9. Martin TV, Behbehani MM (2001) Towards a rational understanding of migraine trigger factors. Headache 85:911-941

10. Olesen J, Goadsby PJ (2000) Synthesis of migraine mechanisms. In: Olesen $\mathrm{J}$, Tfelt-Hansen P, Welch KMA (eds) The headaches. Lippincott Williams Willkins, Philadelphia, pp 331-336

11. Russell MB, Rasmussen BK, Fenger K, Olesen J (1996) Migraine without aura and migraine with aura are distinct clinical entities: a study of 484 male and female migraineurs from general population. Cephalalgia $16: 239-425$
12. Levinton A, Slack VW, Masek B, Bana D, Graham JR (1984) A computerized behavioral assessment for children with headaches. Headache 24:182-185

13. Van der Bergh V, Amery WK, Waelkens J (1987) Trigger factors in migraine: a study conducted by the Belgian Migraine Society. Headache 27:191-196

14. Robbins L (1994) Precipitating factors in migraine: a retrospective review of 494 patients. Headache 34:214-216

15. Scharff L, Turk DC, Marcus DA (1995) Triggers of headache episodes and coping responses of headache diagnostic groups. Headache 35:397-403
16. Bruni O, Fabrizi P, Ottaviano S, Cortesi F, Giannotti F, Guidetti V (1997) Prevalence of sleep disorders in childhood and adolescence with headache: a case-control study. Cephalalgia 17:492-498

17. Chabriat H, Danchot J, Michel P (1999) Precipitating factors of headache: a prospective study in a national control-matched survey in migraineurs and nonmigraineurs. Headache 35:335-338 